\title{
BRINGING IT ALL TOGETHER: NETWORKING HERITAGE INVENTORIES IN ENGLAND
}

\author{
P. K. Carlisle ${ }^{\text {a, } * \text {, E. S. Lee }}{ }^{\text {a }}$ \\ ${ }^{a}$ English Heritage, The Engine House, Fire Fly Avenue, Swindon, SN2 2EH UK - \\ (philip.carlisle, edmund.lee)@english-heritage.org.uk
}

KEY WORDS: heritage inventories, data standards, community projects, interoperability, historic environment, data exchange, open source

\begin{abstract}
:
This paper will look at the requirements for a future vision of networked, digital heritage inventories to support heritage protection in England. The present loose network presents several challenges for multiple organizations maintaining similar datasets on disparate IT software: Duplication of content; ownership of content and different approaches to recording practice and standards. This paper will discuss the potential use of the Arches Heritage Inventory and Management System as part of the vision for better operation of this network. Arches was developed by the Getty Conservation Institute, World Monuments Fund and Farallon Geographics as an open source web-based geographic information system (GIS) to help inventorize and manage immovable cultural heritage. The system is based around internationally recognized standards from both the heritage and IT sectors. These include: ISO 21127: 2006, commonly referred to as the CIDOC-CRM (Conceptual Reference Model); the CIDOC Core Data Standard for Archaeological and Architectural Sites; Core Data Index to Historic Buildings and Monuments of the Architectural Heritage as well as Open Geospatial Consortium (OGC) standards. The proposed use of Arches as a data collection and exchange platform would provide effective and useful recording systems for small heritage projects lacking in-house IT support and the finances and skills to support their development. In addition it would promote standards to support cross-searching, data exchange and digital archiving and through its use of open source a community of IT developers, standards developers and content specialists can be developed to sustain the network.
\end{abstract}

\section{INTRODUCTION}

\subsection{The network of digital heritage inventories in England}

English Heritage is the UK Government's advisor on the historic environment and is responsible for the designation of cultural heritage assets of national importance including both the built and buried heritage as well as the maritime heritage up to the 12-mile limit. To support this function English Heritage maintains a national inventory of non-designated heritage assets, the National Record of the Historic Environment England (NRHE) as well as a statutory dataset of designated (legally protected) assets the National Heritage List for England (NHLE). These provide the national (English) overview and act as a research resource for national-scale studies of the historic environment.

In addition to this national overview each local authority is tasked with maintaining or having access to a Historic Environment Record (HER) for use in assessing the impact of planning applications on cultural heritage sites and monuments in their area, and in engaging communities in valuing and caring for their local heritage.

In addition to these national and local inventories English Heritage and other national grant-giving bodies, fund many community-based and university-based projects undertaken by

special-interest groups and academics which develop datasets and information systems as a product of their work.

Finally, new discoveries are frequently made through commercially-funded investigations carried out by contracting archaeological units. The results of these projects and investigations are then fed into the local and national datasets.

\subsection{Challenges for the network}

There are two major challenges inherent in the operation of the network of heritage inventories. These derive from the nature of the recording of cultural heritage sites, and from the economics of providing services to a small specialist market.

Cultural heritage sites are not museum objects. Similarly the requirements of inventories of these sites are not the same. For any given cultural heritage site, be it an archaeological site or historic building, there are often many organisations that have an interest in it.

\subsection{Challenge 1: Duplication of effort}

Whereas a museum object will generally be documented by a single curating authority, a cultural heritage site - for example a prehistoric burial mound - may be recorded simultaneously

\footnotetext{
* Corresponding author. This is useful to know for communication with the appropriate person in cases with more than one author.
} 
by any combination, or indeed all, of the following: a local authority for assessing and advising on land-use planning and development control purposes; a national body for managing legal protection as it applies to the site; the landowner, as part of land management plans; and a national thematic research project recording burial mounds of that type or date. This fundamental difference presents a substantial technical challenge (Lee, 2005).

For research and public access, the consequence of multiple heritage inventories recording the same cultural heritage site is that to obtain a full picture of the existing knowledge of a site it is often necessary to draw upon information from a variety of different inventories.

One solution is to use aggregator sites and initiatives such as the UK's Heritage Gateway, allow cross-searching of multiple sources. Currently the Heritage Gateway includes 54 resources, 47 of which are local authority HERs. This represents just over half (56\%) of the HERs currently in England.

It provides access to national datasets from English Heritage as well as national, local and regional datasets from local authority Historic Environment Records (HERs), National Park Authorities and charities such as the National Trust. The national datasets include statutory data from the National Heritage List for England (NHLE) and non-statutory data from the National Record of the Historic Environment (NRHE). The NHLE includes all sites and monuments which are currently protected but the details it holds are restricted to the statutory information required by law. The NRHE, on the other hand contains many of the same records but the details are far more comprehensive.

This inclusion of both the NHLE and NRHE data ensures that any search will inevitably return duplicated records for most of the areas covered by a local authority HER.

This multiplicity of data is even further exacerbated if the searches are expanded to include other historic environment information resources (HEIRs) such as those included on the HEIRNET register (Baker, Chitty et al, 2000)

\subsection{Challenge 2: Limited technical solutions}

For the management of information in the sector, the economic challenge of providing services to a diverse but small specialist market is equally profound. The diverse range of uses for cultural heritage site documentation records, and the typically small size of organisations that manage and maintain them means that the market for specialist software to support heritage inventories is small.

In contrast to the many commercial information systems available to manage library, archives or museum collections, the market for information systems for cultural heritage inventories in England is dominated by a single commercial provider (75\% of HERs). The majority of the remainder organizations that do not use this system have developed bespoke systems in-house using proprietary, off-the-shelf, database software such as Microsoft Access.

This monopoly has led to a strange situation where the software supplier is perceived as having the power to influence the development of the standards underpinning recording practice within the heritage sector. Opportunities to embrace new technologies may be stymied by an unwillingness to disturb the status quo or by the costs of redeveloping proprietary software to enable interoperability with emerging open-source tools and standards.

In the current economic climate, there is an increasing need for inexpensive, reliable, standards-based software which allows for the interchange of data not only between national and local datasets but increasingly between these and community-led projects, many of which are often undertaken by volunteers.

\subsection{The future for the network}

The nature of the cultural heritage that we record, and the need for multiple records of the same site will still persist, to meet the different needs of the public and professional audiences.

However, organisational strategy, such as that in development by English Heritage, aims to establish the local authorities as the principle point of access for records of the historic environment. This will help to clarify the situation, and provide much needed support for the resourcing of local authority databases but it will not remove the multiplicity of interest groups. Indeed, with the emergence of community-led recording initiatives, the number of players in the game is likely to rise.

This paper therefore examines the development of a model to complement the provision of top-of-the-range licensed commercial proprietary software with provision of an opensource, license free approach to tackle the second of the two challenges noted above.

\section{STANDARDS AND INTEROPERABILITY}

\subsection{Data Standards}

Since the mid 1990s the development of standards for use in the cultural heritage sector in England has been overseen by the Data Standards Unit (DSU). This unit, part of the Heritage Data Management Section of English Heritage specializes in the development of data standards (such as MIDAS Heritage) and controlled vocabularies (eg. the Thesaurus of Monument Types) and, working in partnership with other cultural heritage organizations that make up the Forum on Information Standards in Heritage (FISH), makes these freely available for use in the wider cultural heritage sector.

Although part of English Heritage, the DSU's remit stretches beyond the geographic borders of England and the UK. Its members have been actively involved at an international level in the development of the CIDOC Core Data Standard for Archaeological and Architectural Sites, the CIDOC CRM (ISO 21127:2006) and the European Heritage Network HEREIN Thesaurus and have provided support to the other UK home nations to allow them to develop their own, regionally-specific controlled vocabularies.

These standards have also been used, within the UK and internationally, to underpin the development of specialist software for use in the cultural heritage sector.

It is in this role, as standards developers that the DSU was approached by Getty Conservation Institute and WMF, for 
advice and guidance on the use of standards and good practice in the development of heritage inventories. Following on from their work on MEGA Jordan the project team wanted to develop software for use in the inventorization of the cultural heritage

The Arches vision, of an open-source, easy-to-use, platform independent software based on recognized international standards was seen by English Heritage as a very exciting prospect and a potential solution to the age-old problem of data exchange between organizations and small community-based projects.

\subsection{English Heritage and the Arches vision}

English Heritage funds many such projects which inevitably involve data collection. The solution so far has been to include a portion of the budget for the development of a database. This approach is not only expensive but within such a large organization, sometimes projects are funded without consideration being given to the underlying structure of the databases being provided.

This leads to problems with data export, data import, inconsistency in the use of terminology and software versioning all of which inevitably mean that some form of human intervention is necessary to manipulate the data into a structure which can then be subsumed into the NRHE and later disseminated to the HERs.

Even when the data is provided in a recognized standardized format the potential for overlap is considerable with the record for the same site or monument existing in multiple datasets.

The potential to use the Arches software as an intermediate information carrier could solve many of the problems currently encountered in the cultural heritage digital network.

Arches is first and foremost being developed as free and open source software (FOSS). Cost is a serious impediment for many cultural heritage organizations and as such open-source software is increasingly being touted as an economical alternative for use in project-based research. This is particularly true for community-based projects which may be reliant upon voluntary contributions.

Furthermore Arches is based on recognized international standards (many of which have been influenced by English Heritage). As such the data structure is already a good match for that in use in EH systems and the entities need only be mapped to the structure of the national dataset to ensure interoperability between the two.

As a result any instances of Arches provided as part of EHfunded projects could be 'seeded' with core records (eg. Bronze Age barrows) and then provided to the project for enhancement/augmentation prior to the results being reimported. This results not only in an enhanced national record but due to the nature of FOSS it allows the project to maintain its own copy of the database for use in future projects or as a searchable web-resource.

English Heritage is also committed to providing reference data as part of the standard Arches package. As such any projects using Arches can, if they so wish, ask for EH reference data to be included.

\section{CONCLUSIONS}

The challenges faced by the UK heritage sector in attempting to provide a network of linked resources will not be solved merely by adopting Arches. Indeed, it may never be adopted by those organizations with an inherent, if somewhat misguided, distrust of open-source software. However it does provide the community with an opportunity to explore the potential of FOSS particularly for use in project-based research. English Heritage has invested considerable time in the development of Arches, particularly in ensuring its compliance with the standards and it is anticipated that following the launch a pilot project will be undertaken to assess its suitability for use in EHfunded projects.

\section{REFERENCES}

Lee, E., 2005. Building Interoperability for United Kingdom Historic Environment Information Resources. D-Lib Magazine 11(6) http://www.dlib.org/dlib/june05/lee/06lee.html (9 Jul. 2013)

Baker, D., Chitty, G., Richards, J., Robinson, D., 2000. Mapping information resources: A report for HEIRNET, Council for British Archaeology, York, UK http://www.archaeologyuk.org/heirnet/rep1.html (9 Jul. 2013)

Watson, T., 2012. MIDAS Heritage: The UK Historic Environment Data Standard (2 ${ }^{\text {nd }}$ edition). English Heritage, Swindon, UK

http://www.english-heritage.org.uk/publications/midasheritage/ (9 Jul. 2013) 